\title{
System for Electronic Archiving of Document in Republic of Kosovo- An Evaluation of Success Factors- Design-Reality Gap Analysis
}

\author{
Phd(c) Fakije Zejnullahu \\ Ministry of Public Administration, Republic of Kosovo \\ Email: fakije_z@hotmail.com
}

\section{Prof. Assoc. Dr. Indrit Baholli}

European University of Tirana

Email: indrit.baholli@uet.edu.al

Doi:10.5901/mjss.2017.v8n1p347

\section{Abstract}

\begin{abstract}
Use of Innovation of ICT in activities of the public sector, referred to as e-Government, has helped governments to improve their services to citizens, to businesses and to government units by making them more qualitative and easily accessible. The initiative of e-Government in Kosovo was identified as a priority of the government in 2008 and since then a number of projects have been implemented, amongst them the System for Electronic Archiving of Document (SEAD). Since the partial or full failure of implementation of e-government projects is very frequent phenomenon in developing countries, the identification of success and failure factors of projects is necessary in order to address them on time. In this study are assessed the level of success of implementation of SEAD and are identified the critical success and failure factors of this system through seven dimensions ITPOSMO by using the Design Reality Gap Analysis. By measuring the design-reality gap across seven dimensions, we have assessed the success of the implementation of SEAD, which scored 18.05. Results from this study indicate that if no action is taken to reduce the size of gaps, particularly the gap in dimensions "Processes" and "Staffing and Skills", project risks falling in the category "Partial Failure". Findings from this research will serve to reduce the risks that may affect the successful implementation of e-governance in Republic of Kosovo, and also will serve other researchers in identifying the failure and success factors of e-Government in developing countries.
\end{abstract}

Keywords: SEAD, ICT, ITPOSMO, e-Government.

\section{Introduction}

Information and Communication Technology has brought dramatic changes in the functioning of global modern society. Evolution of the ICT made the governments to create a new vision for interaction with citizens and businesses.

Governments around the world were directed toward using of ICT innovations to improve the operations of the public sector, to offer to citizens and businesses qualitative services and appropriate access to information, and to improve Democratic Processes. This will drive the movement towards e-Government.

Zhiyuan Fang defines the e-Government as a way for governments to use the most innovative information and communication technologies, particularly web-based Internet applications, to provide citizens and businesses with more convenient access to government information and services, to improve the quality of the services and to provide greater opportunities to participate in democratic institutions and processes. (Fang, 2002)

In 2008, the Government of Kosovo approved "e-Government strategy 2009-2015", thus starting so the egovernment journey. Implementation of e-government in the Republic of Kosovo began in 2009 and since then a number of projects have been implemented, among them the System for Electronic Archiving of Documents (SEAD), which was one of the first initiatives undertaken in the implementation of e-Government program and is implemented in almost all the archives of government institutions.

The Government of Kosovo in 2016 has launched the initiative to link the SEAD with the System for Document Management and elimination of deficiencies that may be identified in SEAD, therefore an assessment of the critical success and failure factors would help to address the shortcomings of the system and an orientation of actions to be taken during the implementation of this initiative.

The analysis was done using the model: Design-Reality Gap Analysis conducted by Richard Heeks. 
The gap between the "real situation" in which the project is currently and "The Project Objectivity" along the seven dimensions of (ITPOSMO) model has been analyzed: Information, Technology, Processes, Objectives and values, Staffing and skills, Management systems and structure, Other resources.

By measuring the size of this gap we assess the level of success, the smaller the gap, the higher the chance for more successful implementation of system. (Heeks, 2003)

\section{System Description}

The System of Electronic Archiving of Documents (SEAD) is a centralized system that has replaced and unified the manual process of archiving of documents and their management. This system is developed in the framework of the eGovernment program (MAP, 2008) and implemented in almost all the institutions of the Republic of Kosovo in central and local level.

The system enables electronic archiving of documents, their destruction by retaining records for any destruction, authorization to access the archived documents and management of the archived matter by keeping track for any action taken by the user at any time.

Seeing the importance of this system, the Government of Kosovo in 2016 has initiated the project for interconnection of this system with the Document Management System, so that these two systems operate as one single system and also eliminate the gaps that could be identified in SEAD.

The unification of these two systems will enable to create an on-line document and protocol it in DMS, circulate it during the entire time while it is active and when it becomes passive, the document with all its descriptive data will be transferred to SEAD, pending to be archived.

The document with its identification data shall be available to the Archive Officer, thus making the archiving process very simple.

The users of this system are the employees who archive the documents in the relevant institutions; therefore the people involved in this research are the Archiving Officials of the institution using this system.

\section{Research Framework}

Although the e-government is seen as a magnificent project, most of the e-government projects have completely or partially failed (Heeks, 2003).

The assessment of the "success" of an information systems is a very important aspect to understand the IS success by assessing the effective creation, distribution, and use of information via technology. This is because every organization would like to ensure that their investments in IS field are successful and to identify whether the system meets the organization's goals (DeLone \& McLean, 2016)

According to Heeks (Heeks, 2002), IS Initiatives may fall into one of the three outcome categories:

Total failure: The initiative never implemented, or was implemented but immediately abandoned.

Partial failure: The main goal of the initiative and/or desired result has not been achieved, or when the initiative initially is successful but after a year or so fails (may affect developing countries)

Success: The initiative is successful when we do not experience significant undesirable outcomes and in which the most of the stakeholder's major goals are attained.

Heeks divides the failure of the e-government projects as below (Heeks, 2003):

$35 \%$ - total failures

$50 \%$ - partial failures

$15 \%$ - successful

One of the most used models for assessment of success factors of Information Systems is the Model: DesignReality Gap Analysis developed by Richard Heeks, a model that has been used in many researches related to the measuring of success and failure of the e-Government initiative in developing countries

Heeks sees the source of a project failure on the size of Design-Reality Gap. The possibility of a project to be successful or to fail, depends on the size of gap between "current reality" in which the project is and "project design'. The larger design-reality gap leads to greater risk of project failure, and vice versa.

In order to understand this gap, gap analysis across seven dimensions of Heek's model, summarized by the ITPOSMO acronym is necessary and sufficient: Information, Technology, Processes, Objectives and values, Staffing and skills, Management systems and structures and Other Resources, which together create a model for assessing the success and failure of the e-government, given under Figure No.1. 
Figure No.1. Design Reality Gap (Heeks, 2003)

\section{Research Methodology}

The research tool for data gathering used in this research is the open data questionnaire (Matthews.B \& Ross.L, 2010). The questionnaire is built based on Heeks model, which covers seven factors: Information, Technology, Processes, Objectives \& Values, Management Systems \& Structures, Staffing \& Skills and Other Resources.

The questionnaire has been conducted in two parts: the first part has been concentrated in questions enabling the collection of demographic data, such as: gender, age, education and working experience, whereas the second part of the questionnaire has been designed to measure seven (7) elements covered by the seven ITPOSMO dimensions:

1. Informaton

2. Technology

3. Processes

4. Objectives and values

5. Staffing and skills

6. Management systems and structures

7. Other Resources

To assess the design-reality gap, the scale from zero to ten has been used for each dimension.

No change
\begin{tabular}{|l|c|c|c|c|c|c|c|c|c|}
\hline 0 & 1 & 2 & 3 & 4 & 5 & 6 & 7 & 8 & 9 \\
\hline
\end{tabular}
"0" -no change between the current reality and design proposal
"5" -some degree of change between the current reality and design proposal
"10" -radical changes between the current reality and design proposal

\section{Statistical Analysis of Collected Data}

The population in this study consists of 76 archive officers who use this system to electronically archive the documents within their institution. A total of 25 questionnaires were distributed via e-mail. 22 questionnaires were received, 2 of them were disqualified due to partial completion, while the rest of the questionnaires, 20 of them were valid.

\subsection{Demographic information}

Table No.1. Provides demographic data for archive officers who participated in this study

\begin{tabular}{|l|l|c|c|}
\hline Variable & Response & Frequency & Percent (\%) \\
\hline \multirow{3}{*}{ Gender } & Male & 10 & 50 \\
\cline { 2 - 4 } & Female & 10 & 50 \\
\hline \multirow{3}{*}{ Education Level } & High school & 4 & 20 \\
\cline { 2 - 4 } & University & 11 & 55 \\
\cline { 2 - 4 } & Master & 5 & 25 \\
\hline \multirow{3}{*}{ Work Experience } & $1-5$ year & 1 & 5 \\
\cline { 2 - 4 } & $6-10$ year & 5 & 25 \\
\cline { 2 - 4 } & over 11 year & 14 & 70 \\
\hline
\end{tabular}




\subsection{Design-reality gap.}

In the diagram below are presented the total points for each dimension. The larger design-reality gap is in the dimensions: Processes, Staffing \& Skills and Objectives \& Values. See Figure No.2

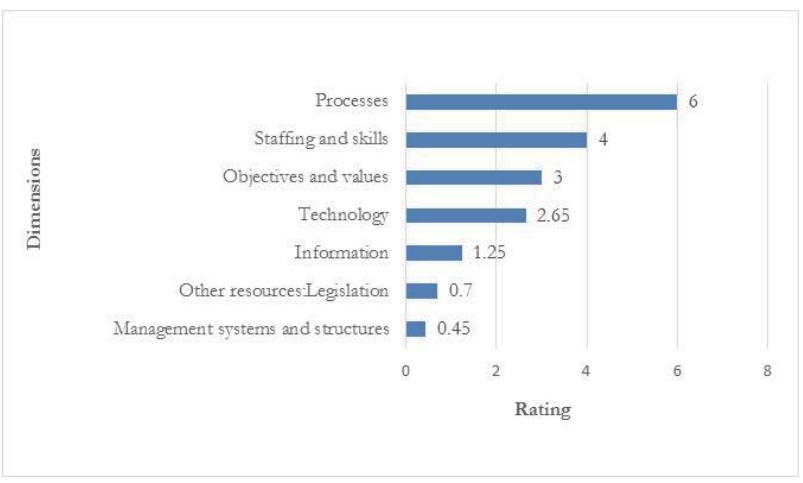

Figure No.2: Diagram of Gaps

\section{Results}

Based on this study, the success of implementation of SEAD is scored 18.05, and falls under the category (15-28)" Your e-government project might be a partial failure unless action is taken to close design-reality gaps", see Table No. 2.

Table No.2. Risk Assessment layout (Heeks, 2003)

\begin{tabular}{|l|l|}
\hline Overall Rating & Likely Outcome \\
\hline $57-70$ & Your e-government project will almost certainly fail unless action is taken to close design-reality gaps. \\
\hline $43-56$ & Your e-government project may well fail unless action is taken to close design-reality gaps. \\
\hline $29-42$ & Your e-government might fail totally, or might well be a partial failure unless action is taken to close design-reality gaps. \\
\hline $15-28$ & Your e-government project might be a partial failure unless action is taken to close design-reality gaps. \\
\hline $0-14$ & Your e-government project may well succeed. \\
\hline
\end{tabular}

Information: Information provided through SEAD is similar to the one in use. This information is accurate, complete, relevant and appropriately presented. $75 \%$ of respondents assess that the use of information is well defined; the information on SEAD should be accessible only to archive officials of the relevant institution, whereas for all other stakeholders, access to this information must be authorized to access certain information, through the function "authorization" which is included in the system. Only $25 \%$ assess that information should be available for the public and others, defined by the law on access to public documents.

Gaps $=1.27$

Technology: In general, respondents estimate that the technology used in SEAD is the right one. $25 \%$ of respondents estimate that their institution needs additional devices for scanning documents, while $20 \%$ estimate that it would be good if the Internet would be a little faster.

Gap=2.65.

Processes: According to respondents, although work processes for archiving files are digitized appropriately, but SEAD should be supplemented with some additional functions. $75 \%$ of respondents (officials) say that other functions should be added to the SEAD such as: electronic seal, electronic signature and communication with DMS.

Gap=6.

Objectives \& Values: Respondents unanimously agree that SEAD has brought more benefit to their work and made it easier, but $75 \%$ of them, say that SEAD does not fully meet their objectives.

Gap=3.

Staffing \& Skills: Respondents say they have sufficient skills to use the system and the user manual available in 
the system helps them a lot. While, $80 \%$ of respondents claim that the number of employees dealing with document archiving in relevant institution is low.

\section{Gap=4.}

Management Systems \& Structures: In this dimension there is no expressed gap between the real situation and design. Only one respondent says that the organizational structure should be changed, because there is no unit for document management, which would deal precisely with this area.

Gap=0.45.

Other Resources: Respondents estimate that the legal framework with regard to document archiving is sufficient. $10 \%$ believe that every institution must have the list of official document classification.

Gap $=0.7$.

\section{Recommendations}

Reducing the size of gaps in dimension" Processes", which in this study is considered to be more critic, it can be done by Interconnection of two systems: "System for Electronic Archiving of Document" with "Document Management System". This interconnection will enable the creation of a unified platform for managing of circulation of documents and organizing the archive of the institution.

This will make easier work of archive officials, since the document created in DMS, it will pass in SEAD in the moment that the document will change the status from active-to-passive. In this case all meta-data that identify the document will be made available electronically for archive officials.

For verifying the identity of a signatory and legal validity of electronic document, we recommend to integrate the electronic seal and electronic signature in the unified platform (SEAD \& DMS). These two elements will facilitate and simplify procedures for electronic identification, validity and authenticity of the document and the automatic sealing of documents.

In order to mitigate the concerns of $80 \%$ of respondents over the low number of employees dealing with document archiving in relevant institution, the institutions may recruit new employees or transfer employees to Archive Offices.

The working group, appointed for implementation of project for connecting of two systems (SEAD) and (DMS), must organize the workshops with archive officers in order to identify their expectation and the shortcomings encountered during use of the SEAD. Identify and addressing of shortcomings of the systems will enable the fulfilment of objectives, through reducing the gap in dimension "Objectives and Values".

The demand for additional equipment's for scanning must be considered and should be treated seriously, since the process of archiving of document cannot be completed without attachment of scanned documents.

As a result not timely treatment of this problem, not make only difficult the process of archiving of documents but will increase the gap even in other dimensions, especially in dimension "Objectives and Values", thus making the system not more valuable to the work of the archive officers

\section{Conclusion}

One of the first initiatives in the implementation of e-government program in the Republic of Kosovo was the initiative to implement a Unified and Centralized System for Electronic Archiving of Documents which will be used in all government institutions. To assess whether this initiative has reached its objectives and to identify the critical factors that could jeopardize the success of the project, the model design-reality gap analysis has been used.

By measuring the gap between the "Actual reality" in which the SEAD is and "what the project should achieve" across seven model dimensions ITPOSMO, we have assessed the success of the implementation of SEAD, which scored 18.05. Results from this study indicate that if no action is taken to reduce the size of gaps, the project risks falling in the category "Partial Failure".

The working group that will implement the project for connecting the System for Electronic archiving of document (SEAD) and Document Management System (DMS) and address the shortcomings of SEAD (project initiated in 2016) must be mobilized to carefully address these gaps, particularly the gap in dimensions "Processes" and "Staffing and Skills" which according to the study are critical factors that can lead the project to partial failure.

Since one of the authors of this study "Fakije Zejnullahu", has managed the implementation of the projects SEAD and DMS and continues to manage the implementation of the initiative for communication of these two systems, there was no limitation in the realization of this study and that the findings in this study will be implemented primarily in the successful realization of the initiative. 


\section{References}

DeLone.H.W \& McLean.R.E. (2016). Information Systems Success Measurement. Foundations and Trends in Information Systems. vol. 2, no. 1, pp. 1-116.

Heeks.R. (2002). Information Systems and Developing Countries: Failure, Success and Local Improvisations. The Information Society. 18(2), 101-112.

Heeks, R. (2003). Most eGovernment-for-Development Projects Fail: How Can Risks be Reduced? (Government working paper series; No. 14). University of Manchester.

Matthews.B \& Ross.L.(2010). Metodat e hulumtimit, Udhëzues praktik për shkencat sociale dhe humane, Tiranë:CDE

Zhiyuan.F. (2002). E-Government in Digital Era: Concept, Practice, and Development. International Journal of The Computer, The Internet and Management. Vol. 10, No.2, p 1-22.

MAP (2008). Strategjia e Qeverisjes Elektronike 2009-2015. [Online] Available: http://map.rks-gov.net/Dokumentet /strategjia_e_qeverisjes_elektronike_2009_2015.aspx (November 20, 20016) 